\title{
Can habitat loss be treated independently of habitat configuration? Implications for rare and common taxa in fragmented landscapes
}

\author{
Paris J. Goodsell, Sean D. Connell* \\ Department of Environmental Biology, University of Adelaide, Adelaide 5005, South Australia, Australia
}

\begin{abstract}
Habitat loss leads to a reduction in number of remnant habitats in continuous landscapes and inevitably leads to increased distances between habitats. We tested the independent and interactive effects of habitat number (number of suitable habitats per unit area) and habitat proximity (distance between these habitats) on assemblages of invertebrates associated with kelp holdfasts (Ecklonia radiata). We tested whether these kinds of habitat modifications have disproportionate effects on rare taxa. Loss and fragmentation of habitat did not operate independently. Patterns of diversity responded markedly to decreases in number of habitats, but this effect was reduced when neighbouring habitats were proximate rather than distant. Rare rather than common taxa primarily responded to these varying aspects of fragmentation. Results highlight the importance of considering the number of suitable habitats in an area (habitat number) when testing the influence of their isolation (habitat proximity) on biodiversity in fragmented landscapes. Awareness that number and proximity of patches are not independent at local scales may provide insights needed to predict the effects of habitat fragmentation on biodiversity, particularly on components of assemblages that tend to be rare.
\end{abstract}

KEY WORDS: Biodiversity · Conservation · Metapopulation · Spatial pattern · Rarity $\cdot$ Edge effects Resale or republication not permitted without written consent of the publisher

\section{INTRODUCTION}

The fragmentation of habitat and concomitant loss of biodiversity is of major concern to ecologists who seek better ways of managing activities of human expansion. 'Habitat fragmentation' is often defined as an increase in distance among habitable patches (habitat proximity) and/or a reduction in the number of remnant habitats (habitat number); (reviews: Andrén 1994, Zuidema et al. 1996). Two paradigms dominate current research, the species-area relationship and the speciesisolation relationship (McArthur \& Wilson 1967, Hanski 1994). Greater rates of extinction occur in landscapes with fewer, or smaller patches that constrain the total inhabitable area and numbers of individuals critical to sustain breeding (Simberloff 2000). Rates of

${ }^{*}$ Corresponding author. E-mail: sean.connell@adelaide.edu.au colonisation to distant patches of habitat may decrease because dispersal is diminished by increased risks associated with travelling larger distances through relatively inhospitable areas (Johnson et al. 1992). Small populations are more likely to become extinct (review: Gilpin \& Soulé 1986), hence rare species, either because they occupy a small number of habitats or because they make up a small proportion of total abundance among habitats, are likely to be sensitive to the adverse effects of modification of habitat.

The loss of habitat (decrease in number of remnant habitats) inevitably leads to an increase in distance between habitats within a landscape. Although the term 'habitat fragmentation' is often used to imply both of these processes, few have attempted to separate their effects (Fahrig 1998, Trzcinski et al. 1999). The realisation that isolation and number of habitats must be negatively correlated at some scale provides no conceptual difficulty, but ecologically, dispersive 
and/or sessile animals may respond very differently to these 2 aspects of modification of habitat (Kareiva 1983, Kunin 1997).

We tested the independent and interactive effects of habitat number (number of suitable habitats per unit area) and habitat proximity (distance between these habitats) on assemblages of invertebrates associated with kelp holdfasts (Ecklonia radiata). We specifically tested whether rare taxa (taxa that occur in low abundance and frequency among habitats) are disproportionately affected. The system we used to provide this assessment was the speciose assemblage of marine invertebrates associated with holdfasts of monospecific forests of the macroalgae Ecklonia radiata. Holdfasts are habitat for a diverse assemblage of mobile and sessile invertebrates (up to 386 species from 152 families and 10 phyla within 250 holdfasts, Smith et al. 1996) and such speciose assemblages tend to have a high proportion of rare species (Gaston 1994).

Each holdfast forms a discrete unit of habitat surrounded by relatively barren substratum (Melville \& Connell 2001) forming effective patches of habitat needed to test hypotheses about isolation of habitats (Hanski 1994). There has been some disquiet about definitions of what constitutes a patch, but most agree that an effective patch is an area of habitat surrounded by areas of non-habitat (Hanski 1999). Non-habitat (e.g. the matrix of bare substratum between holdfasts in kelp forests) provides resistance to migrating animals (Fahrig \& Merriam 1994, Ricketts 2001), isolating animals to patches of elevated resources (e.g. food, shelter, space). This use of small individuals (e.g.

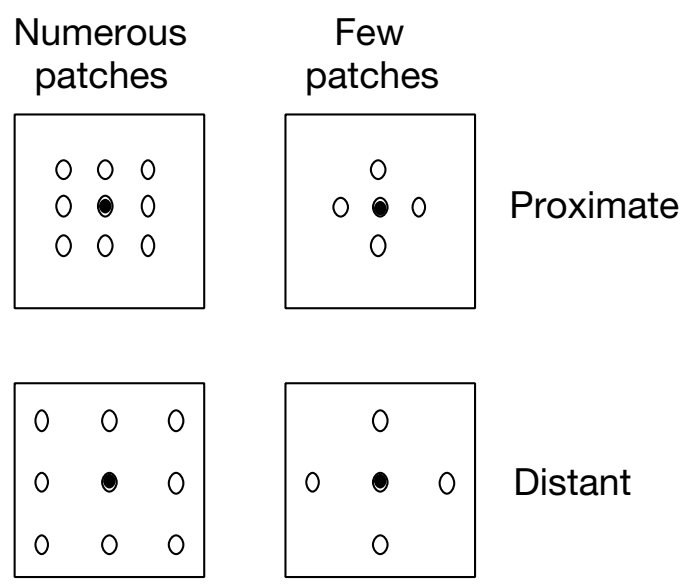

Fig. 1. Diagram illustrating how number and proximity of habitats (patches) were manipulated in independent combinations to test their interactive effects on diversity at the scale of a metre square. (O) Habitats (holdfasts), (•) holdfast that was sampled. Squares represent the area $\left(1 \mathrm{~m}^{2}\right)$ from which habitats were cleared to create these configurations. The area outside each square represents natural (untouched) forests marine invertebrates) in small-scale experiments can provide useful insights into the responses of natural assemblages to modification of habitat (Wiens \& Milne 1989, Underwood \& Skilleter 1996) and confer cost and time advantages since smaller individuals often respond faster to habitat modification (Roff 1992).

\section{MATERIALS AND METHODS}

Forests with numerous or few habitats at their edges and centres. We sampled invertebrate assemblages from holdfasts of Ecklonia radiata which form monospecific stands of macroalgae (hereafter referred to as 'forests') to test whether the position of holdfasts to edges of forests and number of habitats within forests affected diversity and should be considered experimentally. This preliminary work was done in the belief that experimental tests require reference to the natural world so that there is some biological basis for the interpretation of experimental outcomes (Underwood et al. 2000).

Assemblages of invertebrates from the holdfasts of Ecklonia radiata were collected during March 2000 (Austral autumn) at a depth of 3 to $6 \mathrm{~m}$ within 2 sites (>50 $\mathrm{m}$ apart) at Edithburgh, South Australia (35 $5^{\circ} \mathrm{S}$, $\left.137^{\circ} 45^{\prime} \mathrm{E}\right)$. At each site, 2 positions within a forest were sampled; 'edges' of forest, quadrats of contiguous forest directly adjacent to areas devoid of E. radiata (e.g. sandy substrate); and 'centres' of forest, quadrats at least $1 \mathrm{~m}$ away from an edge. Experimental tests have shown that high and low densities of E. radiata within $1 \mathrm{~m}^{2}$ cause considerable differences to the ecology of understorey species of algae (Melville \& Connell 2001). Hence, numbers of E. radiata (holdfasts) within quadrats were counted and defined as either 'few' ( 1 to 5 plants $\mathrm{m}^{-2}$ ) or 'numerous' ( $>5$ plants $\mathrm{m}^{-2}$ ). Holdfasts were sampled in orthogonal fashion such that forests with few or numerous E. radiata were sampled at their edges and centres $(n=6)$ at each of 2 sites ( $\mathrm{n}=48$ holdfasts in total).

Manipulation of number and proximity of habitats. In June 2000 (Austral winter) we independently manipulated the number of holdfasts $\mathrm{m}^{-2}$ (habitats) and the distances between holdfasts (habitats) in an orthogonal configuration. This manipulation provided 4 combinations of each factor ( 2 number $\times 2$ proximity) with 6 replicate holdfasts (Fig. 1). Forests with naturally numerous habitats were thinned to have few habitats by haphazard removal of plants. Proximity was manipulated by removing all neighbouring plants within $<10 \mathrm{~cm}$ (treatment = proximate) to $>20 \mathrm{~cm}$ (treatment $=$ distal) from an experimental plant (Fig. 1). These proximities represented the natural range of distances among holdfasts in forests at these sites (3 to $18 \mathrm{~cm}$ and 
21 to $45 \mathrm{~cm}$ ). A large number of marine invertebrates disperse over regional distances (Eckman 1996) but this study tests whether local variation in spatial arrangements of habitats can influence biodiversity.

Artefacts associated with the experimental removal of kelp were evaluated by testing for differences between disturbed forests (thinned) and undisturbed forests (natural) of the equivalent density (see Underwood 1986 on the logic of testing for experimental artefacts). We compared samples from forests with naturally few habitats to those that had been thinned to have few habitats and compared forests with naturally numerous habitats to forests from which some holdfasts were removed but numerous habitats still remained. Any differences between these controls and the treatments would indicate an effect of the manipulations (removal of kelp) that is not associated with the quantity or proximity of holdfasts. The experiment was run for $2 \mathrm{mo}$, a much greater time than is required for large changes in such invertebrate assemblages, which can occur within days (e.g. Gunnill 1982, Bell \& Hicks 1991).

Sampling methods. Holdfasts were removed for sampling by cutting the stipe at the base of the laminae and sealing an open plastic bag around the stipe and holdfast. The holdfast was levered off the substratum into the bag with a dive knife and the bag was quickly closed over the holdfast. Holdfasts were stored in $10 \%$ formalin/seawater solution and then the haptera of each holdfast was dissected and the contents of the holdfast sieved through a $1 \mathrm{~mm}$ sieve to separate the fauna. Where possible, animals were identified to species and specimens were stored in $90 \%$ alcohol and kept as a specimen library. Because the volume of holdfasts is known to influence biodiversity (Smith et al. 1996), holdfasts of similar size were collected and these did not differ among treatments (Site, Position, Number and Proximity) nor were there interactions between these experimental factors (ANOVA: $\mathrm{p}>0.05$ ).

Analytical methods. Two-way NP-MANOVA (Anderson 2001) on Bray-Curtis distances (Faith et al. 1987) of fourth root transformed data (Clarke 1993) tested the relative and interactive (1) associations between number (numerous vs few) and position (edge vs centre) of habitats and (2) experimental effects of number (numerous vs few) and proximity (distant vs proximate) of habitat. Analyses were done (1) for each 'Site' and treated 'Position' and 'Number' as fixed and orthogonal to each other and (2) and treated 'Proximity' as fixed and orthogonal to the fixed factor 'Number'. A constrained ordination (Canonical discriminant analysis; Legendre 1990) was used to provide a visual assessment of the effects of experimental treatments on patterns of diversity. Group differences were not apparent in nMDS plots (stress > 0.20; Clarke 1993), possibly because of the highly dimensional nature of the data (i.e. large number of taxa).

To test the hypothesis that rare rather than common species are primarily affected by the experimental modification of habitat we repeated the multivariate analysis of fourth root transformed data on rare and common taxa separately. If rare rather than common taxa primarily contributed to multivariate patterns observed for the whole assemblage, these additional analyses should detect the same patterns for rare but not common taxa. We defined 'rare' as taxa that occurred in low frequency (present in $<20 \%$ the experimental holdfasts) and low relative abundance (contributed to $<1 \%$ of the total number of individuals). We defined 'common' as taxa that occurred in high frequency (present in $>50 \%$ of the experimental holdfasts) and high relative abundance (contributed to $>1 \%$ of the total number of individuals). These cut off were based on comparisons among the 81 experimental taxa (see results).

Definitions of rarity and commonness are necessarily arbitrary (Gaston 1994). Without applying arbitrary cut-offs, we used transformations (presence/absence, fourth root and untransformed data) to provide an additional test of the contribution of rare taxa to experimental effects. Presence/absence transformation is thought of as the ultimate transformation in downweighting the effects of common taxa (Clarke \& Warwick 1994). However, taxa that appear in all samples (an aspect of commonness) cannot discriminate between treatments, and thus do not contribute to multivariate patterns of presence/absence datasets. Only taxa that are patchy, those absent from some samples (an aspect of rarity), can discriminate between treatments of the same analysis. Hence, this aspect of rarity (absence from some samples rather than relative abundance among samples) is emphasised by our use of presence/absence. Fourth root transformations reduce the effects of numerically large values (i.e. abundant taxa), thereby increasing the contribution of rare taxa to measures of dissimilarity (Clarke 1993). This transformation has become somewhat of a standard in ecological tests because it focuses attention on patterns within the whole assemblage rather than on the most abundant taxa of the assemblage. For these reasons, we used fourth root transformation when testing the effects of treatments on rare and common taxa. Furthermore, comparison of fourth-root transformed with untransformed data of the whole assemblage was used to indicate the effect of treatments on taxa whose abundance is disproportionately large.

Univariate ANOVA was used to test whether the number of species differed among positions, quantities and sites. 'Site' was treated as a random factor and 
Table 1. NP-MANOVA testing the effects of habitat patch number (few vs numerous) at 2 positions within forests (edge vs centre) at 2 sites (1 vs 2). Transformations gave equal weight to rare through common taxa (presence/absence), slightly greater weight to common/abundant taxa (fourth root) and substantial weight to common/abundant taxa (no transformation). ${ }^{*} \mathrm{p}<0.05$

\begin{tabular}{|c|c|c|c|c|}
\hline Factor & $\mathrm{df}$ & $\begin{array}{c}\text { Presence/ } \\
\text { absence } \\
F\end{array}$ & $\begin{array}{c}\text { Fourth root } \\
\text { F }\end{array}$ & $\begin{array}{c}\text { None } \\
\text { F }\end{array}$ \\
\hline \multicolumn{5}{|l|}{ (a) Site 1} \\
\hline Position & 1 & 0.608 & 0.920 & 1.667 \\
\hline Number & 1 & $1.979^{*}$ & $1.911^{*}$ & 1.479 \\
\hline Position $\times$ Number & 1 & 1.208 & 1.143 & 0.824 \\
\hline Residual & 20 & & & \\
\hline \multicolumn{5}{|l|}{ (b) Site 2} \\
\hline Position & 1 & 0.959 & 0.997 & 0.955 \\
\hline Number & 1 & $1.915^{*}$ & $1.720^{*}$ & 1.179 \\
\hline Position $\times$ Number & 1 & 0.573 & 0.535 & 0.497 \\
\hline Residual & 20 & & & \\
\hline
\end{tabular}

orthogonal to the fixed factors 'Number' and 'Position'. ANOVA was also used to test for differences among and within quantities and proximities where both factors were treated as fixed and orthogonal to each other.

\section{RESULTS}

Forests with numerous or few habitats at their edges and centres

The number of habitats had significant effects on the presence/absence of taxa and their relative abundances when analyses provided for a reduced influence of abundant taxa (fourth root transformation), but

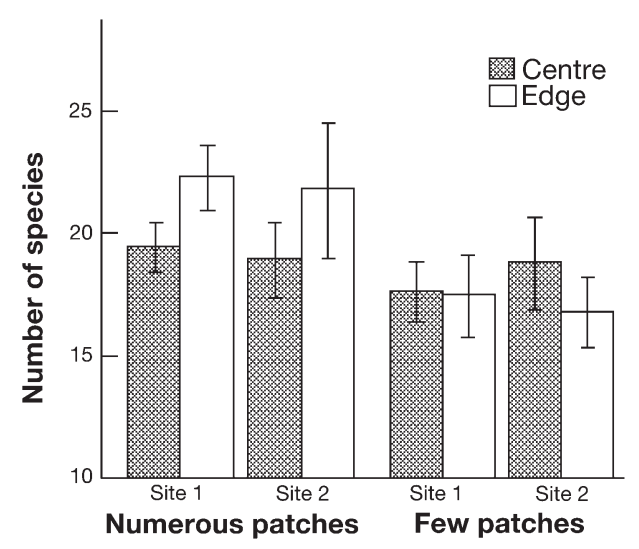

Fig. 2. Mean number of taxa $( \pm \mathrm{SE})$ in forests with numerous ( $>5$ plants $\mathrm{m}^{-2}$ ) and few ( 1 to 5 plants $\mathrm{m}^{-2}$ ) habitat patches at their centres and edges at each of 2 sites $(n=6$ habitats treatment ${ }^{-1}$ ) not when analyses reduced their influence (no transform, Table 1). These results appear robust given that these effects were detected at each of 2 sites. No significant difference in these multivariate measures was detected between edges and centres of kelp forests (Table 1).

There were more species in forests with numerous habitats than in those with few (Fig. 2: Table 2 and SNK tests). No particular taxon appeared to be consistently present in forests with numerous habitats and absent from forest with few habitats. The invertebrate assemblage was extremely diverse with on average 170 individuals and 53 taxa from at least 30 families within holdfasts sampled from forests with numerous habitats. Within forests with few habitats there were, on average, 144 individuals and 48 taxa from at least 28 families.

\section{Experimental effects of number and proximity of habitats}

A significant interaction between 'number' and 'proximity' was detected for (1) species composition (presence/absence; $p=0.017$ ) and (2) their relative abundance (fourth root transformation; $\mathrm{p}=0.027$; Fig. 3, Table 3). The distances between habitats only affected measures of diversity (composition, relative abundance) when forests had few rather than many habitats. Importantly, reducing the number of habitats only affected biodiversity when habitats were distant, rather then proximate. Taken with the initial description of patterns of biodiversity, it appears that areas with few habitats have large effects on taxa, particularly if habitats are distant.

Table 2. ANOVA testing differences in number of invertebrate taxa between number of habitats (numerous vs few) at 2 positions within forests (edge vs centre) at 2 sites. Post-hoc pooling of the interaction term (Number $\times$ Site: $p>0.25$; Winer et al. 1991) with the residual enabled a more powerful test of the main factor 'Number'. The resultant values are indicated by ' $a$ '. Values were homogenous at $p>0.05$, Cochran's C-test. 'Position' and 'Number' were treated as fixed and orthogonal each other and to the random factor 'Site'. NS, p > 0.05

\begin{tabular}{|lrrcc|}
\hline Source of variation & df & \multicolumn{1}{c}{ MS } & $F$ & $\mathrm{p}$ \\
\hline Number & 1 & 105.021 & $7.61^{\mathrm{a}}$ & 0.009 \\
Position & 1 & 9.188 & 3.64 & $\mathrm{NS}$ \\
Site & 1 & 0.188 & $0.01^{\mathrm{a}}$ & $\mathrm{NS}$ \\
Number $\times$ Position & 1 & 46.021 & 18.26 & $\mathrm{NS}$ \\
Position $\times$ Site & 1 & 2.521 & $0.18^{\mathrm{a}}$ & $\mathrm{NS}$ \\
Number $\times$ Site & 1 & 1.688 & $0.12^{\mathrm{a}}$ & $\mathrm{NS}$ \\
Number $\times$ Position $\times$ Site & 1 & 2.521 & $0.18^{\mathrm{a}}$ & $\mathrm{NS}$ \\
Residual & 40 & 14.104 & & \\
& & & & \\
\hline
\end{tabular}


None of these effects were detected when the contribution of abundant species was not reduced (no transformation) in the calculation of Bray-Curtis measures of dissimilarity (Table 3 ) or in the analysis of common taxa (NP-MANOVA on interaction term: $F_{1,20}$ p $>0.05$ ). Analysis of rare taxa, however, revealed the same multivariate patterns detected for the whole assemblage (NP-MANOVA on interaction term: $F_{1,20}, \mathrm{p}<0.05$ and pairwise tests). Methods used to define 'rare' and 'common' are seldom explained, probably because such definitions tend to be arbitrary and specific to the assemblage from which it was defined (Gaston 1994). Our study offers no exception. The experimental assemblage comprised of 1668 individuals from 81 taxa for which the most abundant taxon contributed $10 \%$ to total abundance (164 of 1668 individuals). Hence, commonly used cut offs to define rarity (e.g. $<5$ to $10 \%$ of total abundance) were not useful to characterise rarity in our specious assemblage. Of the 81 taxa, we were able to repeatedly assign 40 taxa as rare and 22 taxa that were common, but 19 did not clearly fit into either category and were omitted from ancillary analyses of rare and common taxa.

Univariate ANOVA failed to detect any differences between the number of species between treatments $\left(F_{1,20}=0.03, \mathrm{p}>0.05\right)$, which suggests that changes in composition rather than number of taxa accounts for most of the variation observed.

Comparison of forests with naturally few habitats to thinned forests failed to detect any artefacts associated with the experimental removal of kelp for each type of transformation (NP-MANOVA: $F_{1,20 ;}$ p > 0.05). Similar comparison of disturbance within forests with numer-

Table 3. (a) NP-MANOVA testing the effects of habitat patch number (numerous vs few) and proximity (proximate vs distant). Transformations gave equal weight to rare through common taxa (presence/absence), slightly greater weight to common/abundant taxa (fourth root) and substantial weight to common/abundant taxa (no transformation). (b) Pairwise tests are provided beneath significant interaction terms. ${ }^{*} p<0.05$

\begin{tabular}{|c|c|c|c|c|c|c|c|}
\hline \multicolumn{2}{|c|}{$\begin{array}{l}\text { (a) NP-MANOVA } \\
\text { Factor }\end{array}$} & df & \multicolumn{2}{|c|}{$\begin{array}{c}\text { Presence/absence } \\
F\end{array}$} & \multicolumn{2}{|c|}{$\begin{array}{c}\text { Fourth root } \\
F\end{array}$} & $\begin{array}{l}\text { None } \\
\quad F\end{array}$ \\
\hline \multicolumn{2}{|l|}{ Proximity } & 1 & \multicolumn{2}{|c|}{1.270} & \multicolumn{2}{|c|}{1.288} & 1.219 \\
\hline \multicolumn{2}{|l|}{ Number } & 1 & \multicolumn{2}{|c|}{1.373} & \multicolumn{2}{|c|}{1.39} & 1.309 \\
\hline \multicolumn{2}{|c|}{ Proximity $\times$ Number } & 1 & \multicolumn{2}{|c|}{$1.813^{*}$} & \multirow{2}{*}{\multicolumn{2}{|c|}{$1.646^{*}$}} & 1.199 \\
\hline \multicolumn{2}{|c|}{ Residual } & 20 & & & & & \\
\hline \multicolumn{3}{|c|}{ (b) Pairwise comparisons } & $t$ & $\mathrm{p}$ & $t$ & $\mathrm{p}$ & \\
\hline \multicolumn{8}{|l|}{ Proximity } \\
\hline Proximate & \multicolumn{2}{|c|}{ Few vs numerous } & 1.232 & NS & 1.175 & NS & - \\
\hline $\begin{array}{l}\text { Distant } \\
\text { Number }\end{array}$ & \multicolumn{2}{|c|}{ Few vs numerous } & 1.289 & 0.034 & 1.281 & 0.020 & - \\
\hline Few & \multicolumn{2}{|c|}{ Proximate vs distant } & 1.297 & 0.038 & 1.252 & 0.045 & - \\
\hline Numerous & \multicolumn{2}{|c|}{ Proximate vs distant } & 1.179 & NS & 1.164 & NS & - \\
\hline
\end{tabular}

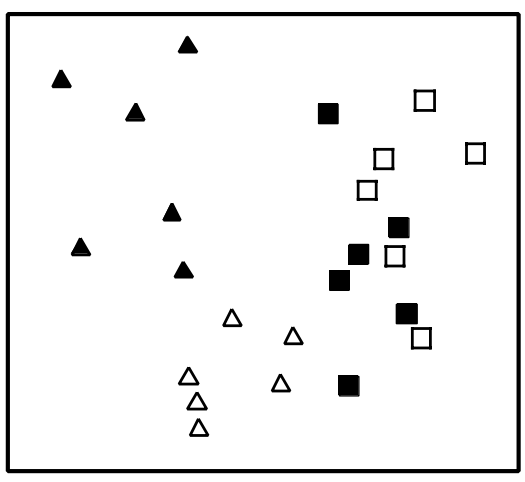

Fig. 3. Canonical ordination of diversity in forests with $\mathbf{\square}=$ numerous, distal habitats; $\square=$ numerous, proximate habitats;

$\Delta=$ few, distal habitats; $\Delta=$ few, proximate habitats

ous habitats also failed to detect differences in these measures (NP-MANOVA: $F_{1,20 ;} \mathrm{p}>0.05$ ). These comparisons test the effects of thinning (disturbance) because the only difference between treatments is the application of disturbance. Because we did not detect such differences, our experimental effects reflect the intended effect of each treatment rather than artefacts associated with disturbances of thinning.

\section{DISCUSSION}

Our results highlight the importance of considering the number of suitable habitat patches in an area (habitat number) when testing the influence of habitat isolation on biodiversity. Patterns of diversity showed a marked response to reductions in quantity of habitats (patches), yet this was mediated when neighbouring habitats were proximate. This study is one of the few attempts to separate the effects of habitat loss (number of habitats) and habitat fragmentation (proximity of habitats) in independent manipulations of natural assemblages. Recent studies have suggested that loss of habitat has a greater influence on population dynamics relative to habitat fragmentation (break up of continuous habitat) which only affects abundances in landscapes with a small amount of habitat (Andrén 1994, Fahrig 1998, Trzcinski et al. 1999). Our results support generalisations that habitat proximity is important in areas with few rather than 
many habitats, but warn that loss and isolation of habitat do not always operate independently of each other, because the effects of loss (i.e. the remaining number) can be mitigated by proximity of neighbouring habitats.

The responses we detected most likely stem from changes in the rates of movement of individuals among patches (habitats), rather than demographic change. We speculate that areas with few and distant habitats will accelerate population change because of the combination of a reduced capacity to disperse to neighbouring habitats (associated with their proximity) and fewer chances of finding new habitats (associated with their number). Loss of taxa occupying distant habitats will not be as severe, if there are numerous surrounding habitats (as related to greater total area) providing greater opportunities for dispersal (and breeding). Predictions about animal movement from patterns of distribution may be possible (Crowe 1996), and a useful topic for future research would be to test predictions about the rate of colonisation of invertebrates in such spatial arrangements of habitat.

Rare species were strongly affected by the spatial configuration of habitats, more so than were common and abundant species. The effects of habitat fragmentation were only detected in analyses from which common species were omitted and in analyses that gave equal or near more weight to rare and common taxa. That is, taxa that occurred in small frequencies among habitats (i.e. number of habitats with taxon present) and small relative abundance (i.e. number relative to total number of taxa) were primarily responsible for causing these differences to be detected. While there are many definitions of rarity and methods used to identify rare species (Gaston 1994) our analyses are persuasive. Without applying arbitrary cut-offs, multivariate analyses reveal that transformations that gave equal weight to rare and common species (presence/ absence) detected strong affects of fragmentation, but this effect was weakened (fourth root transformation) and obliterated (no transformation) when the contribution of common taxa was increased.

Our use of transformations to assess whether rare species were disproportionately affected by the experimental treatments is unlikely to be useful for multivariate tests of all assemblages and certainly does not address all aspects of rarity. Presence/absence transformations, for example, may provide tests of rarity for assemblages containing taxa frequently absent from samples (one aspect of rarity) because taxa that appear in all samples (one aspect of commonness) cannot discriminate between treatments. The arbitrary classification of taxa as 'rare' is standard in ecology (Gaston 1994), but suffers from subjectivity because the exercise lacks repeatability among observers and assem- blages. Such inadequacy points to the need for the greater development of methods to identify and assess rarity, understanding that one quantitative measure or test may not capture all aspects of rarity.

That rare species are disproportionately affected by loss and fragmentation of habitat has been reported for other assemblages of invertebrates (Didham et al. 1998, Golden \& Crist 1999). Invertebrates with pelagic larval dispersal (e.g. polychaetes \& echinoderms) are proposed to have better dispersive capabilities than do those with brooding or direct development (e.g. crustaceans) (Christie et al. 1998). These predictions were not supported because numbers of species in all major groups (polychaetes, bryozoans, crustaceans and echinoderms) was not different among various levels of modification of habitat. Furthermore, rare species are present in all these major groups. Loss of rare species due to modification of habitat might be expected from predictions of small populations (Wilcox 1980, Tilman et al. 1994). Yet it is unknown whether the abundance and distribution of species is related to other characteristics thought to infer greater susceptibility to fragmentation, such as large body-size, speciality for habitat, low reproductive and dispersal capacity (Gaston 1994, Tilman et al. 1994). Controversy exists not only over whether these traits increase susceptibility to extinction, but whether traits of rare species (if any) make them more prone to extinction than is the case for common species (Terborgh \& Winter 1980, Wilcox 1980, Kunin \& Gaston 1993).

Our results indicate that identifying rarity within habitats may be a crucial component of understanding the effects of fragmentation on biodiversity. Unfortunately, it is common practice for ecologists to omit rare species from multivariate analyses of assemblage structure (Cao et al. 1998) because they seldom affect their outcomes (Gauch 1982). Exclusion of rare species in studies of fragmentation may be desirable for statistical reasons (e.g. Laurance et al. 2001), but may lead to unacceptable loss of ecological information. We acknowledge that the choice of whether or not to include rare species is necessarily based on providing appropriate (sensible and logically derived) and adequate (statically exhaustive) tests of a priori hypotheses. There can be no general rule, but we argue that tests about the effects of fragmentation on biodiversity will reasonably require inclusion of all species in analyses if rare species are disproportionately affected by changes to structure of habitat. Currently, there is insufficient information to make generalisations about the vulnerability of rare taxa (Lawton 1995), but in the absence of such knowledge it would seem prudent to include them in tests of factors influencing biodiversity.

Despite statistical realities that make it difficult to detect the effects of disturbances on rare taxa, it 
appears that attempts to do so are entirely possible. This is particularly likely to be true in assemblages with larger numbers of taxa (e.g. 81 taxa from 33 families, present study), which tend to have larger proportions of rare taxa (Gaston 1994). Multivariate measures of similarity have been criticised because they strongly underweight rare species (low numeric values) and overweight abundant species (Cao et al. 1998), but our results demonstrate that these techniques can be used to identify impacts on rare species by using a variety of analytical procedures.

In conclusion, it is not possible to distinguish between components of habitat fragmentation in many natural systems because of restrictions on the number of habitats, sizes and extent to which they can be isolated. Our study was able to separate the effects of number and proximity of habitats (patches) to assess their interactive effects on biodiversity. Predictions that fragmentation becomes important when the amount of habitat is small (Andrén 1994, Fahrig 1998) are supported in this study, but we show that the spatial pattern of habitat can compensate for the decrease in diversity associated with loss of habitat per se. At many scales, number and proximity of habitats are not independent, so both measures could provide substantial insights into unravelling the role of isolation of habitat on biodiversity, particularly components of the assemblage that tend to be rare.

Acknowledgements. Special thanks to Tony Underwood for providing substantial improvements to the manuscript and forcing us to think harder about our approach to and interpretation of analyses. Maren Wellenreuther, Stafford Goodsell, Ben Leonello, Meegan Fowler-Walker, Jeremy Gramp and Saul Michaelis bravely assisted in the cold field conditions. This research was support by ARC grants to SDC.

\section{LITERATURE CITED}

Anderson MJ (2001) A new method for non-parametric multivariate analysis of variance in ecology. Austral Ecol 26: $32-46$

Andrén H (1994) Effects of habitat fragmentation on birds and mammals in landscapes with different proportions of suitable habitat: a review. Oikos 71:355-366

Bell SS, Hicks GRF (1991) Marine landscapes and faunal recruitment: a field test with seagrasses and copepods. Mar Ecol Prog Ser 73:61-68

Cao Y, Williams DD, Williams NE (1998) How important are rare species in aquatic community ecology and bioassessment. Limnol Oceanogr 43:1403-1409

Christie H, Fredriksen S, Rinde E (1998) Regrowth of kelp and colonization of epiphyte and fauna community after kelp trawling at the coast of Norway. Hydrobiologia 375/376: $49-58$

Clarke KR (1993) Non-parametric multivariate analyses of changes in community structure. Aust J Ecol 18:117-143

Clarke KR, Warwick RM (1994) Change in marine communi- ties: an approach to statistical analysis and interpretation. Natural Environmental Research Council, UK

Crowe T (1996) Different effects of microhabitat fragmentation on patterns of dispersal of an intertidal gastropod in two habitats. J Exp Mar Biol Ecol 206:83-107

Didham RK, Hammond PM, Lawton JH, Eggleton P, Stork NE (1998) Beetle species responses to tropical forest fragmentation. Ecol Monogr 68:295-323

Eckman JE (1996) Closing the loop: linking larval ecology to the population dynamics of marine benthic invertebrates. J Exp Mar Biol Ecol 200:207-237

Fahrig L (1998) When does habitat fragmentation of breeding habitat affect population survival? Ecol Model 105: 273-292

Fahrig L, Merriam G (1994) Conservation of fragmented populations. Cons Biol 8:50-59

Faith DP, Minchin PR, Belbin L (1987) Compositional dissimilarity as a robust measure of ecological distance. Vegetatio 69:57-68

Gaston KJ (1994) Rarity. Chapman and Hall, London

Gauch HG (1982) Multivariate analysis in community ecology. Cambridge University Press, Cambridge

Gilpin ME, Soulé ME (1986) Minimum viable populations: Processes of species extinction. In: Soulé ME (ed) Conservation biology: The science of scarcity and diversity. Sinauer Associates, Sunderland, MA, p 19-34

Golden DM, Crist TO (1999) Experimental effects of habitat fragmentation on old-field canopy insects: community, guild and species responses. Oecologia 118:371-380

Gunnill FC (1982) Effects of plant size and distribution on the numbers of invertebrate species and individuals inhabiting the brown alga Pelvetia fastigiata. Mar Biol 69: 103-116

Hacker SD, Steneck RS (1990) Habitat architecture and the abundance and body-size-dependent habitat selection of a phtytal amphipod. Ecology 71:2269-2285

Hanski I (1994) Patch-occupancy dynamics in fragmented landscapes. Trends Ecol Evol 9:131-135

Hanski I (1999) Metapopulation ecology. Oxford University Press, Oxford

Johnson AR, Wiens JA, Milne BT, Crist TO (1992) Animal movements and population dynamics in heterogenous landscapes. Landsc Ecol 7:63-75

Kareiva P (1983) Influence of vegetation texture on herbivore populations: resource concentration and herbivore movement. In: Denno RF, McClure MS (eds) Variable plants and herbivores in natural and managed systems. Academic Press, London, p 259-286

Kunin WE (1997) Population biology and rarity: on the complexity of density-dependence in insect-plant interactions. In: Kunin WE, Gaston KJ (eds) The biology of rarity: causes and consequences of rare-common differences. Chapman and Hall, London, p 150-173

Kunin WE, Gaston KJ (1993) The biology of rarity: patterns, causes and consequences. Trends Ecol Evol 8:298-301

Laurance WF, Perez-Salicrup D, Delamonica P, Fearnside PM, D'Angelo S, Jerozolinski A, Pohl L, Lovejoy TE (2001) Rain forest fragmentation and the structure of Amazonian liana communities. Ecology 82:105-116

Lawton JH (1995) Population dynamic principles. In: Lawton JH, May RM (eds) Extinction rates. Oxford University Press, Oxford, p 147-163

Legendre P (1990) Quantitative methods and biogeographic analysis. In: Garbary DJ, South RG (eds) Evolutionary biogeography of the marine algae of the North Atlantic. NATO ASI Series, Vol G 22. Springer-Verlag, Berlin, p 9-34 
MacArthur RH, Wilson E (1967) The equilibrium theory of island biogeography. Princeton University Press, Princeton, NJ

Melville AJ, Connell SD (2001) Experimental effects of kelp canopies on subtidal coralline algae. Austral Ecol 26: 102-108

Ricketts TH (2001) The matrix matters: effective isolation in fragmented landscapes. Am Nat 158:87-99

Roff DA (1992) The evolution of life histories. Chapman \& Hall, New York

Simberloff D (2000) Extinction-proneness of island speciescauses and management implications. Raffles Bull Zool 48:1-9

Smith SDA, Simpson RD, Cairns SC (1996) The macrofaunal community of Ecklonia radiata holdfasts: description of the faunal assemblage and variation associated with differences in holdfast volume. Aust J Ecol 21:81-95

Terborgh J, Winter B (1980) Some causes of extinction. In: Soulé ME, BA Wilcox (eds) Conservation biology: an evolutionary-ecological perspective. Sinauer Associates, Sunderland, MA, p 119-134

Tilman D, May RM, Lehman CL, Nowak MA (1994) Habitat destruction and the extinction debt. Nature 371: 65-66

Trzcinski MK, Fahrig L, Merriam G (1999) Independent

Editorial responsibility: Roger Hughes (Contributing Editor), Bangor, Wales, UK effects of forest cover and fragmentation on the distribution of forest breeding birds. Ecol Appl 9:586-593

Underwood AJ (1986) The analysis of competition by field experiments. In: Kikkawa J, Anderson DJ (eds) Community ecology: pattern and process. Blackwell Scientific Press, Melbourne, p 240-268

Underwood AJ, Skilleter GA (1996) Effects of patch-size on the structure of assemblages in rock pools. J Exp Mar Biol Ecol 197:63-90

Underwood AJ, Chapman MG, Connell SD (2000) Observations in ecology: you can't make progress on processes without understanding the patterns. J Exp Mar Biol Ecol 250:97-115

Wiens JA, Milne BT (1989) Scaling of 'landscapes' in landscape ecology, or, landscape ecology from a beetle's perspective. Landsc Ecol 3:87-96

Wilcox BA (1980) Insular ecology and conservation. In: Soulé ME, Wilcox BA (eds) Conservation biology - an evolutionary - ecological perspective. Sinauer Associates, Sunderland, MA, p 95-117

Winer BJ, Brown DR, Michels KM (1991) Statistical principles in experimental design. McGraw-Hill, New York

Zuidema PA, Sayer JA, Dijkman W (1996) Forest fragmentation and biodiversity: the case for intermediate-sized conservation areas. Environ Conserv 23:290-297

Submitted: October 23, 2001; Accepted: May 2, 2002

Proofs received from author(s): August 2, 2002 